See Article page 1581.

\section{Commentary: The vexing association between imaging and acute kidney injury}

\author{
Megan Rashid, MD, and John Butterworth, MD
}

Acute kidney injury (AKI) robustly predicts postoperative mortality; therefore, its early recognition and treatment are priorities. ${ }^{1}$ In this issue of the Journal, Waheed and $\mathrm{Choi}^{2}$ address contrast dye-induced kidney injury, an issue of concern to nearly every reader of the Journal. They argue against the prevailing "wisdom" regarding the role of iodinated contrast in causing AKI. Their summary of the most recent research is timely, given that AKI is much more common than we'd care to admit, and our best indicators detect the disease itself rather guiding us how to prevent AKI.

However, it's complicated! There is almost never a single, identifiable cause, that but for its presence AKI would not have occurred. The patient populations cared for by the readers of the Journal typically have acute or critical illness and a need for contrast-enhanced imaging. When there are multiple risk factors, it is often impossible with the currently available testing to identify a specific cause of AKI. In the meantime, there is value in identifying promptly those patients with AKI, as well as those who have increased susceptibility to nephrotoxicity, with or without use of contrast. We agree with the authors' opinion that as biomarkers become more affordable and are more rigorously studied, we may better gauge risk and more accurately identify the actual incidence of contrast-associated AKI.

Nevertheless, biomarkers will not be a panacea for the diagnosis and management of AKI. Even when we know that a patient carries increased risk for AKI, imaging studies with contrast remain unavoidable when they diagnose or

\footnotetext{
From the Division of Critical Care, Department of Anesthesiology, Virginia Commonwealth University Health System, Richmond, Va.

Disclosures: The authors reported no conflicts of interest.

The Journal policy requires editors and reviewers to disclose conflicts of interest and to decline handling or reviewing manuscripts for which they may have a conflict of interest. The editors and reviewers of this article have no conflicts of interest.

Received for publication July 22, 2020; revisions received July 22, 2020; accepted for publication July 23, 2020; available ahead of print July 25, 2020.

Address for reprints: Megan Rashid, MD, Department of Anesthesiology, VCU Health System, Box 980695, Richmond, VA 23298-0695 (E-mail: Megan. rashid@vcuhealth.org).

J Thorac Cardiovasc Surg 2021;162:1587

$0022-5223 / \$ 36.00$

Copyright (c) 2020 by The American Association for Thoracic Surgery

https://doi.org/10.1016/j.jtcvs.2020.07.074
}

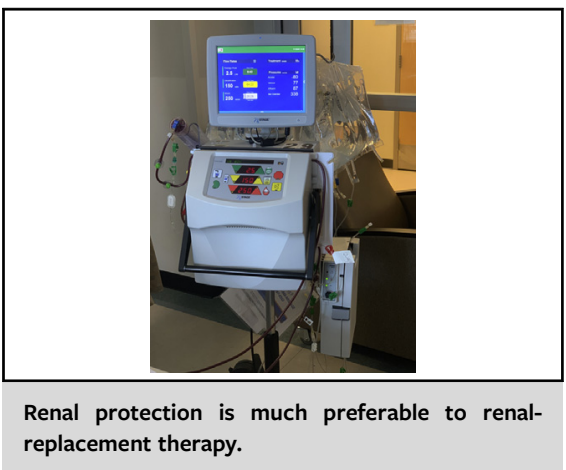

CENTRAL MESSAGE

Contrast media-associated

acute kidney injury remains a

vexing, sometimes-unavoidable

problem in cardiovascular and

thoracic surgical patients.

rule out pathologies requiring immediate, life-preserving interventions. The authors (and we) recommend further research on the AKI disease process, but we suspect that the real game changer for contrast-induced injury will come from improvements in imaging: a reduced volume of contrast media, less nephrotoxic contrast media, or techniques that require no contrast media at all. However, what can we do today? Given the consistent association of hypovolemia, hypotension, and reduced cardiac output with AKI, we strongly advocate for the use of noninvasive monitors (eg, of stroke volume) and diagnostic devices (bedside ultrasound) to avoid these renal insults in patients with critical illness and those undergoing major surgery.

It's true that we have an incomplete understanding of the role iodinated contrast media plays in the pathophysiology of AKI. In the meantime, to do the best for our patients, we must use the evidence we have. Since we can identify AKI only when damage is done, we advocate for a "renal-protective strategy" that carefully evaluates choice and amount of contrast, pays meticulous attention to intravenous fluid management, and avoids nephrotoxic agents as much as possible throughout every patient's hospital stay.

\section{References}

1. Corredor C, Thomson R, Al-Subaie N. Long-term consequences of acute kidney injury after cardiac surgery: a systematic review and meta-analysis. J Cardiothorac Vasc Anesth. 2016;30:69-75.

2. Waheed S, Choi M. Trials and tribulations of diagnosing and preventing contrast-induced acute kidney injury. J Thorac Cardiovasc Surg. 2021;162: 1581-6. 